\title{
Ecofriendly sustainable synthetized nano-composite for removal of heavy metals from aquatic environment
}

\author{
Mohamed Farouz $^{1}$-S. I. El-Dek ${ }^{2}$ Mohamed M. ElFaham ${ }^{1,3} \cdot$ Usama Eldemerdash $^{1,4}(\mathbb{D}$
}

Received: 5 October 2021 / Accepted: 19 December 2021 / Published online: 14 February 2022

(C) The Author(s) 2022

\begin{abstract}
The toxicity of heavy metals in the aquatic environment is a serious challenge to the global community. Even at low concentrations, heavy metals have a cumulatively destructive effect on living organisms in the aquatic environment. Biomass wastes have been investigated for heavy metals removal in the published literature; however, the low performance and capacity of the biomass represents a drawback towards effective application. Therefore, in this study, biomass waste such as corn leaves that have low cost is investigated as a precursor for eco-friendly sustainable nanostructured composite. In this research, several experiments have been conducted focusing on upgrading the capacity of the bioresource for removing heavy metals from the aquatic environment. In addition to low-cost biomass material, nanomaterials such as zinc oxide represents an attractive combination for effective removing heavy metals such as iron and nickel ions. Characterization of the synthesized composite material was conducted using XRD-FESEM-mapping and EDX-HRTEM and SAED-Zeta size and Zeta potential. Moreover, studying the efficiency of synthesized nano-composite for heavy metals ions adsorption of iron and nickel ions shows an outstanding increase of performance. The results suggest that adding nanomaterial to biomass matter and obtaining a composite at nanosize, enables the increase of the adsorption efficiency of heavy metals.
\end{abstract}

Keywords Bioresource $\cdot$ Heavy metals $\cdot$ Adsorption $\cdot$ Biomass $\cdot$ Nano-composite

\section{Introduction}

Biomass wastes represent attractive low-cost materials for solving major environmental problems such as heavy metals in the aquatic environment. With the growth of serious problems for the environment due to the rising concentration of toxic contaminants, there is an imperative need for developing healthy, low cost and eco-friendly materials to detox and purify water sources and to protect the environment

\section{S. I. El-Dek}

samaa@psas.bsu.edu.eg

$\triangle$ Usama Eldemerdash usama.nour@bhit.bu.edu.eg

1 Basic Engineering Sciences Department, Benha Faculty of Engineering, Benha University, Banha, Egypt

2 Materials Science and Nanotechnology Department, Faculty of Postgraduate Studies for Advanced Sciences (PSAS), Beni-Suef University, Beni-Suef 62511, Egypt

3 Pyramids Higher Institute for Engineering and Technology, Giza 12451, Egypt

4 Higher Technological Institute, 10th of Ramadan City, Egypt health (Babel and Kurniawan 2003). Pollution of water resources with heavy metals leads to contamination of the food chain as it represents a major threat to the ecosystem of the planet (Gupta 2009). Accordingly, there is a serious gap of knowledge and need for more research that can contribute to solving this crisis related to water purification, improving its quality, and the possibility of reusing wastewater in agriculture, for example, instead of wasting it. Many treatment techniques are available with varying degrees of success to control water contamination (Gupta et al. 2009). However, the limitations of most of these techniques are high functioning and preservation costs and the complex process of the treatment. Comparatively, the adsorption process is considered a good alternative for water treatment because of its ease of operation (Ahmaruzzaman and Gupta 2011). Biomass sorbents are considered worldwide adsorbents for wastes are generally used for the removal of different contaminants from water. Many adsorbents of low-cost have been studied for their ability to remove several types of contaminants from wastewater (Mohan et al. 2014). Comparatively, the adsorption process is considered a good alternative for water treatment because of its

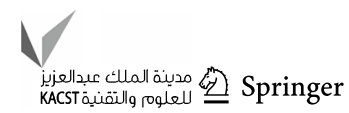


ease of operation (Lankathilaka et al. 2021; Tansir Ahamad et al. 2020). In this study, bio-adsorbents efficiency will be enhanced by adding a nanomaterial to produce a synthetic nano-composite. In this work, corn leaves, $\mathrm{ZnO}$ and synthesized nanocomposite will be examined for removing iron and nickel ions from the water environment. Recent studies have shown that at least some of the NPs can be absorbed in water treatment. The newly emerging field of nanotechnology offers a potential offer for water purification with low cost, high work efficiency in removing contaminants and the ability to be reused again. Shortly, the study of nanoparticles in water purification is considered to evaluate positive standpoints (Fernando et al. 2020; Xiao-long et al. 2020). Several treatment techniques are available with varying degrees of success to control water contamination (Zhaojin et al. 2021; Yaowei et al. 2021). However, the limitations of these techniques are high functioning and preservation costs (Aruna et al. 2021; Ahmed et al. 2021). Many low-cost adsorbents have been studied for their ability to remove several types of contaminants from wastewater (Jingjing et al. 2021; Aya et al. 2021). In this work, corn leaves, $\mathrm{ZnO}$ and synthesized nanocomposite will be examined for removing iron and nickel ions from the water environment.

\section{Materials and methods}

\section{Biomass precursor and synthetic metal solution}

A $500 \mathrm{mg}$ corn leaves (CL) (Egyptian origin planted near Cairo) and $250 \mathrm{mg}$ of nanoparticles $(\mathrm{ZnO})$ (synthesized by our lab) (Aya et al. 2021) were used in each experiment, nanocomposite material consisting of $250 \mathrm{mg}$ of (waste corn leaves and $\mathrm{ZnO}$ in a 1:1 ratio). Iron sulphate $\left(\mathrm{Fe}_{2} \mathrm{SO}_{4}\right)$ supplied by Merck was used to prepare synthetic water with a concentration of $38.33 \mathrm{mg} / \mathrm{L}$. Nickel sulphate $\left(\mathrm{NiSO}_{4}\right)$ supplied by Merck was used to prepare synthetic water with a concentration of $10 \mathrm{mg} / \mathrm{L}$. The $\mathrm{pH}$ of the water samples was adjusted during experimental work using $(0.1 \mathrm{M})$ $\mathrm{HCl}$ to reduce the $\mathrm{pH}$ or $(0.1 \mathrm{M}) \mathrm{NaOH}$ to raise the $\mathrm{pH}$ when required. In all measurements, glass containers were employed to prevent metal ions from being absorbed into the walls of the containers housing.

\section{Biomass preparation}

A biomass waste of (corn leaves) was prepared after carefully choosing samples of organic matter (corn leaves) and ensuring that there were no contaminants, bacteria, or other dangerous substances adhered to the corn leaves. The samples were thoroughly washed and dried in a drying oven that is specifically used for drying purposes for $48 \mathrm{~h}$ at a temperature of $50{ }^{\circ} \mathrm{C}$. After complete drying of the sample, it is subjected to grinding multiple times to confirm that the samples were within the desired size range. The powder resulted from the grinding process is sieved with different mesh sizes until it reaches the desired size of less than $0.5 \mathrm{~mm}$. Glass containers were used to store the samples, which were maintained dry and free from moisture.

\section{Preparation of nanocomposite}

Zinc oxide $(\mathrm{ZnO})$ used in the experimental work of this study was kept in an inert atmosphere using deoxygenated distilled water. The following chemical process was used for the preparation of the nanocomposite (Medha et al. 2021):

1. Biomass $(1000 \mathrm{mg})$ was disseminated in $(200 \mathrm{ml})$ distilled water $120 \mathrm{~min}$.

2. $\mathrm{ZnO}(1000 \mathrm{mg})$ was homogenized in $100 \mathrm{ml}$ distilled water for $30 \mathrm{~min}$.

3. The two mixes were combined of nanoparticles $\mathrm{ZnO}$ and corn leaves to make nanocomposite and held in the ultrasonic probe in an iced water bath for $30 \mathrm{~min}$ to provide heating or drying of the samples.

All samples were collected by centrifugation and dried for $48 \mathrm{~h}$ at $50^{\circ} \mathrm{C}$.

\section{Characterization of materials}

X-ray diffraction (XRD) was examined by (202964 PAN analytical Empyrean) using CuKa radiation $(\lambda=1.54060 \AA)$ under the operating conditions of $30 \mathrm{~mA}$ and $40 \mathrm{kV}$. The scanning range was from $5^{\circ}$ to $80^{\circ}$ with a step size of $0.04^{\circ}$ and a time per step of $0.5 \mathrm{~s}$. Adsorbent's morphology was determined by the scanning electron microscope (ZEISS Gemini Scanning Electron Microscope). The morphology was depicted using Quanta FEG 250 (Czechoslovakia) field emission scanning electron microscopy (FESEM). The microstructure was examined using high-resolution transmission electron microscopy (HRTEM) model JEOL-JEM 2100 (Japan) with an acceleration voltage of $200 \mathrm{kV}$. The zeta potential was measured by Zetasizer Nano-Zs90 (Malvern, UK). The measurements were performed by withdrawing $10 \mu \mathrm{l}$ of (corn leaves, $\mathrm{ZnO}$ and nanocomposite) suspension and followed by dilution in $1 \mathrm{ml}$ of distilled water.

\section{Adsorption experiment}

Five hundred milligrams of solid biomass waste powder (corn leaves) was added to $50 \mathrm{ml}$ of the solution prepared heavy metals (iron $40 \mathrm{ppm}$ and nickel $16 \mathrm{ppm}$ ) at different $\mathrm{pH}$. The beakers were held on an electric shaker, the sample fluid was collected from the mixture every $15 \mathrm{~min}$ to record a reading of heavy metal concentration using atomic 
absorption spectroscopy and to compute the removal efficiency. To modify the acidity and/or alkalinity, a high-precision solution $(\mathrm{HCl})$ and/or $(\mathrm{NaOH})$ was added with a hightech pipette to control the addition. The $\mathrm{pH}$ was determined using $\mathrm{pH}$ Meter equipment (Quimis; model Q400AS) (with a range of $\mathrm{pH} 3-6)$. The adsorption effectiveness of waste biomass (corn leaves) for heavy metal ion removal was investigated (iron and nickel). In all experiments, the adsorbent dosage was (500 $\mathrm{mg}$ biomass, $250 \mathrm{mg} \mathrm{ZnO}$ nanoparticles and $250 \mathrm{mg}$ nanocomposite).

\section{Results and discussion}

\section{X-ray diffraction (XRD)}

XRD diffraction patterns of the three synthesized samples are illustrated in Fig. 1a-c. The patterns look very impressive because of the different crystalline phases depicted. The corn leaves were found to be amorphous where one broad hump was seen at $2 \theta \approx 21$. The $\mathrm{ZnO}$ nanoparticles pattern was compared and indexed with the JCPDS file no. (04-0166646). As it was observed, the nanoparticles $\mathrm{ZnO}$ were crystallized in hexagonal symmetry belonging to the space group P63mc(186) with two molecules per unit cell. The peaks are representative of nine reflections and many planes of the standard ZnO (Ferin et al. 2021; Rajesh et al. 2020) were of low intensities when compared to the bulk counterpart. These findings are characteristic of nanoscale dimensions. The reflections are depicted, indexed and reported in Table 1. The microstrain was found to have larger values and depends strongly on the diffraction angle. This is correlated to the hexagonal symmetry and the preferential. This is correlated
Table 1 Structural parameters of $\mathrm{ZnO}$ nanoparticles

\begin{tabular}{llrll}
\hline $2 \theta\left({ }^{\circ}\right)$ & $d$ value $(\AA)$ & \multicolumn{1}{c}{$I / I_{\mathrm{o}}$} & Microstrain & $(\mathrm{hkl})$ \\
\hline 31.8132 & 2.81292 & 57.26 & 0.404925 & 100 \\
34.5356 & 2.59716 & 56.06 & 0.371260 & 002 \\
36.2723 & 2.47670 & 100.00 & 0.244802 & 101 \\
47.6460 & 1.90867 & 26.89 & 0.456261 & 102 \\
56.6734 & 1.62422 & 37.29 & 0.309894 & 110 \\
62.9257 & 1.47705 & 35.65 & 0.272966 & 103 \\
68.0341 & 1.37805 & 25.23 & 0.196178 & 112 \\
69.1876 & 1.35787 & 14.50 & 0.291751 & 201 \\
77.1309 & 1.23665 & 3.66 & 0.337868 & 202 \\
\hline
\end{tabular}

to the hexagonal symmetry and the preferential $c$-axis in the crystal. The crystalline size was computed using Debye Scherrer's formula and found to be $30 \mathrm{~nm}$ which is relatively small in hexagonal crystals. The nanocomposite pattern in XRD looks to be as crystalline nanoparticles embedded on an amorphous layer of the corn leaves. The pattern was distinguished by four main peaks of very small intensities and broad width. This is mainly due to the existence of $50 \%$ weight of corn leaves in the nanocomposite under investigation. The peaks are also shifted due to the above-mentioned reasons. For the nanocomposites, and from the main diffraction peak, the crystallite was calculated to be $8 \mathrm{~nm}$. Which will be a key factor in the removal of heavy metals.

\section{Field emission scanning electron microscope (FESEM)}

The surface morphology of the studied samples, whether corn leaves, $\mathrm{ZnO}$, or the formed nanocomposite, was
Fig. 1 a-c XRD of corn leaves, $\mathrm{ZnO}$ and nanocomposite

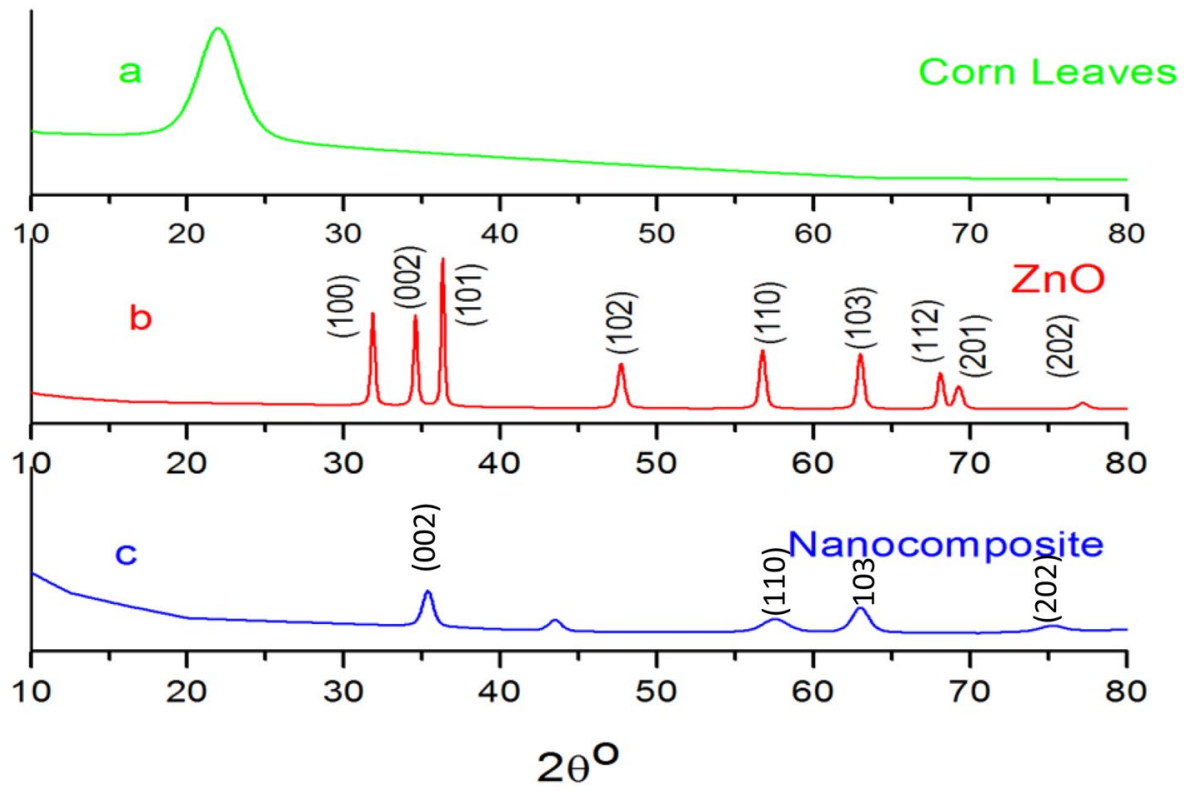


investigated using field emission scanning electron microscope (FESEM). From the modest magnifications up to $300,000 \times$, it displays structural and elemental data. Computer software was used to make the micrographs at various magnifications. The original morphology of the corn leaf is illustrated in Fig. 2a-d, which provides information on the imaging and surface arrangement of the sample. The primary structure of $C L$ is a rough surface. The literature indicates high cellulose content, low hemicellulose content, and low lignin content, which has been employed for various heavy metal absorption abilities (Jingjing et al. 2021). The leaves were found to have curls of their ends and rolled sheets. Even at lesser magnifications, pores and micro-cracks may be detected in the samples. The $\mathrm{ZnO}$ nanoparticles looked to have clear hexagonal plated with different sizes around $30-40 \mathrm{~nm}$ on average the slight wale scene is due to the absence of the surfactant as clear in Fig. 3a-d. Figure 3a, $\mathrm{b}$ clarified the successful formation of $\mathrm{ZnO}$ decorated on the surface of the corn leaves. The nanocomposite was found to be a wrinkled sheet decorated with ultrafine nanoparticles at higher magnifications as shown in Fig. 4a-d.

\section{Mapping and EDX}

The mapping of the nanocomposite ( $\mathrm{ZnO}$ and corn leaves) sample is presented in Fig. 5; the elements of $\mathrm{C}, \mathrm{O}, \mathrm{Na}$, $\mathrm{Cl}, \mathrm{K}$ and $\mathrm{Zn}$ were detected. The weight percentage of the major elements was analyzed on the spectrum surface by the EDX. The electron image from Fig. 5a, shows that the nanocomposite contains many crystalline grains; this is a result of the formation of white colour minerals by the pores present in the material's structure. Figure 6 shows EDX of the corn leaves and nanocomposite. The elements detected by EDX on the sample surface were $61.45 \%$ of C, $23.28 \%$ of $\mathrm{O}, 13.85 \%$ of $\mathrm{Zn}, 0.6 \%$ of $\mathrm{Cl}$ and $0.83 \%$ for $\mathrm{K}$. Table 2 shows the mapping of nanocomposite (corn leaves and $\mathrm{ZnO}$ ) (Table 3).

\section{HRTEM and selected SAED}

High-resolution transmission electron microscopy was used to study the microstructure of the produced samples in greater detail (HRTEM). Micrographs of corn leaves at various magnifications are shown in Fig. $7 \mathrm{a}-\mathrm{c}$, using a micrograph's scale bar, the morphology of the corn leaves particle size was assessed. Furthermore, the shells of the corn leaves were made up of nanoparticles with a cubic form and an average diameter of ( $\mathrm{nm})$, resulting in a corn-leaveslike structure. The SAED illustrate in Fig. $7 \mathrm{~d}$ is a large spot identifying the amorphous nature of the corn leaves which is in good agreement with the pattern of XRD Fig. 1a. Figure $8 \mathrm{a}-\mathrm{c}$ also depicts the morphology microstructure of $\mathrm{ZnO}$ at various magnifications. The particles are hexagonal with an average particle size of $(50 \mathrm{~nm})$. In Fig. 8d, the SAED shows preferred orientation as diffraction rings are pointing to an excellent crystallinity. This preferred orientation is certainty correlated to the hexagonal symmetry of the $\mathrm{ZnO}$ crystal. In addition, Fig. 9a-c depicts micrographs of corn leaves- $\mathrm{ZnO}$ nanocomposites at various magnifications. The $\mathrm{ZnO}$ particles and corn leaves were not chemically reacted. The SAED here for the nanocomposite Fig. 9d is interesting as the poor crystallinity predominates. Two diffraction rings
Fig. 2 FESEM of corn leaves, a $40 \mu \mathrm{m}, \mathbf{b} 20 \mu \mathrm{m}, \mathbf{c} 10 \mu \mathrm{m}$, d $4 \mu \mathrm{m}$

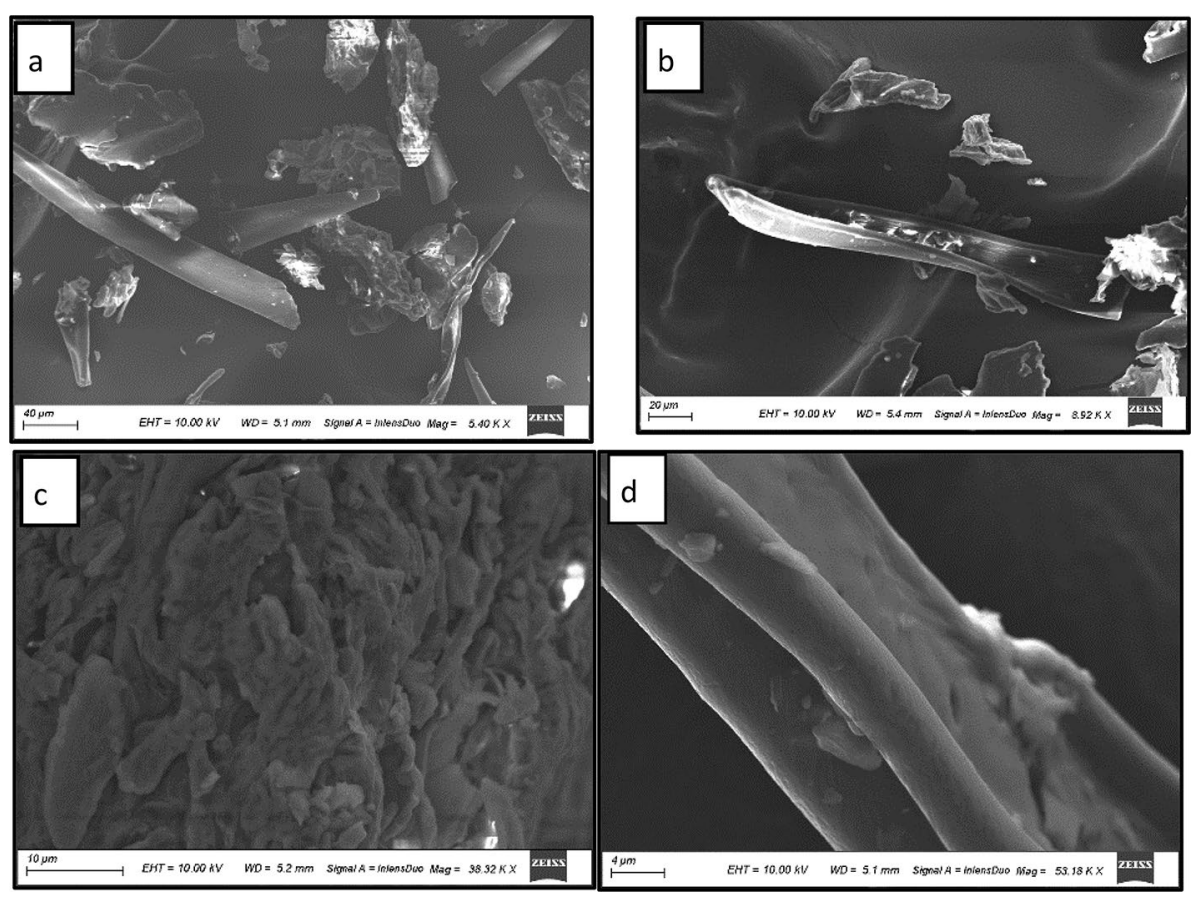



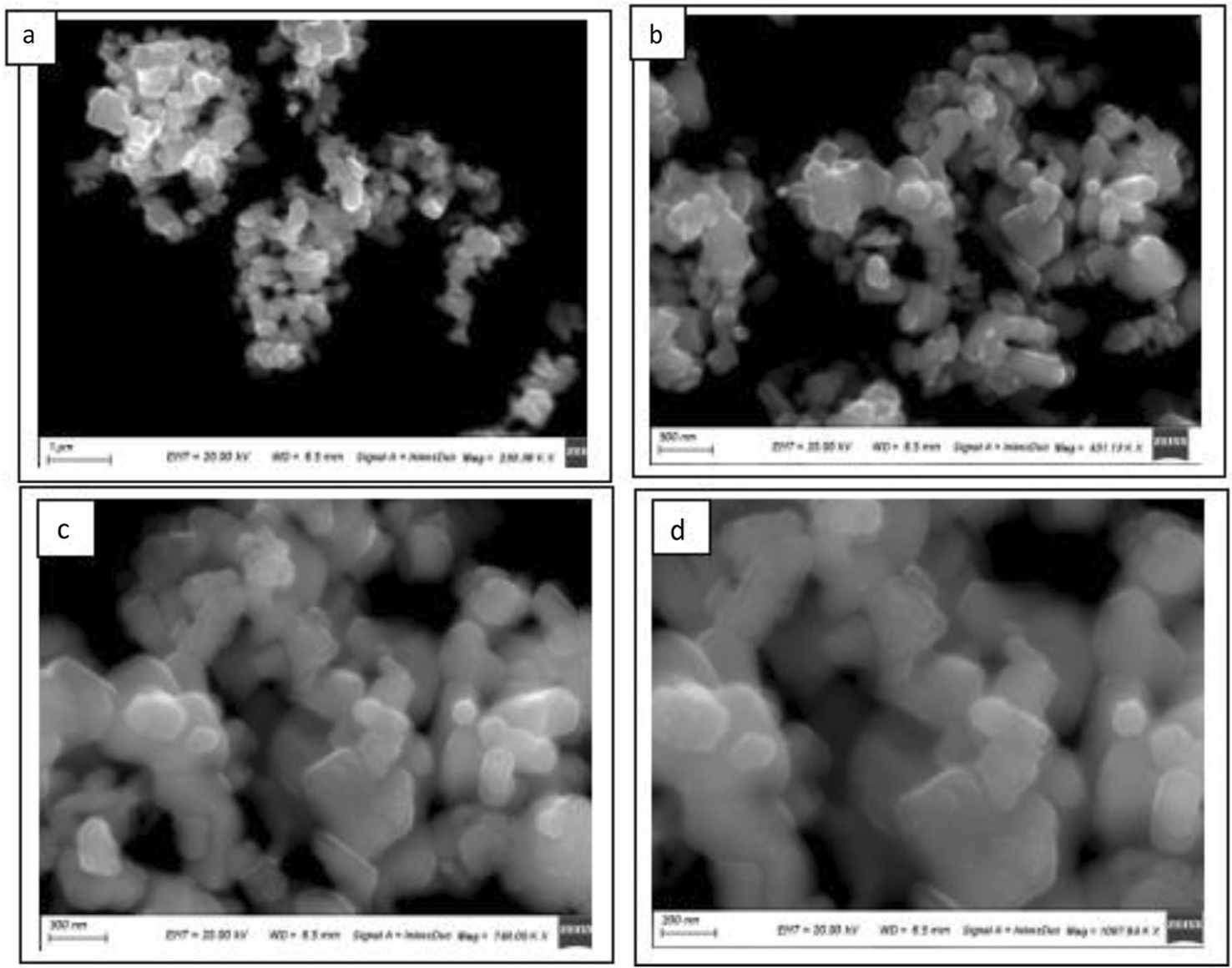

Fig. 3 FESEM of nano-ZnO, a $1 \mu \mathrm{m}$, b $500 \mathrm{~nm}, \mathbf{c} 300 \mathrm{~nm}, \mathbf{d} 200 \mathrm{~nm}$

Fig. 4 FESEM of Nanocomposite, a $10 \mu \mathrm{m}, \mathbf{b} 5 \mu \mathrm{m}, \mathbf{c} 2 \mu \mathrm{m}, \mathbf{d}$ $400 \mathrm{~nm}$
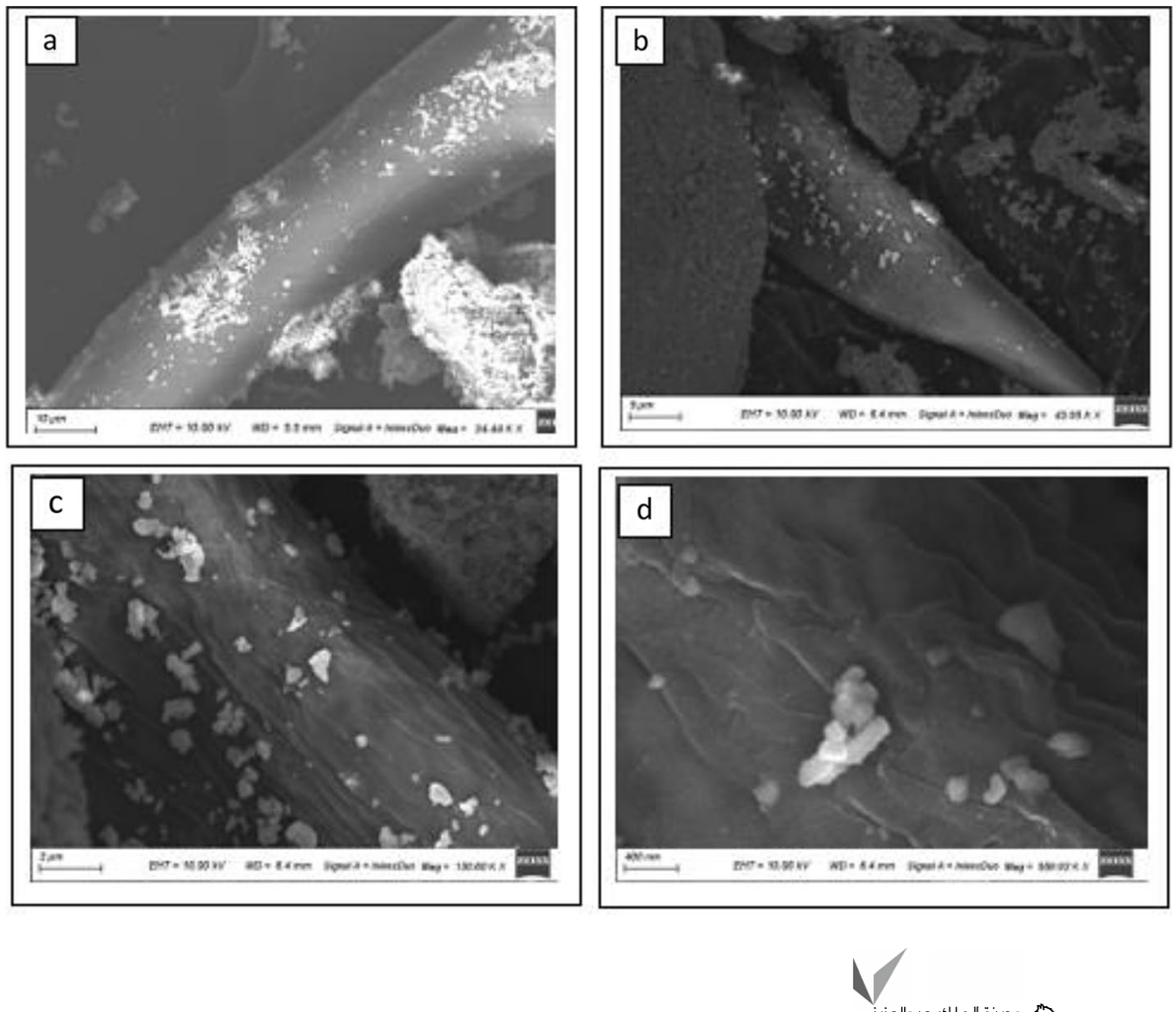

Springer 
Fig. 5 Mapping of nanocomposite, $\mathbf{a}-\mathbf{g}$ (corn leaves and $\mathrm{ZnO})$
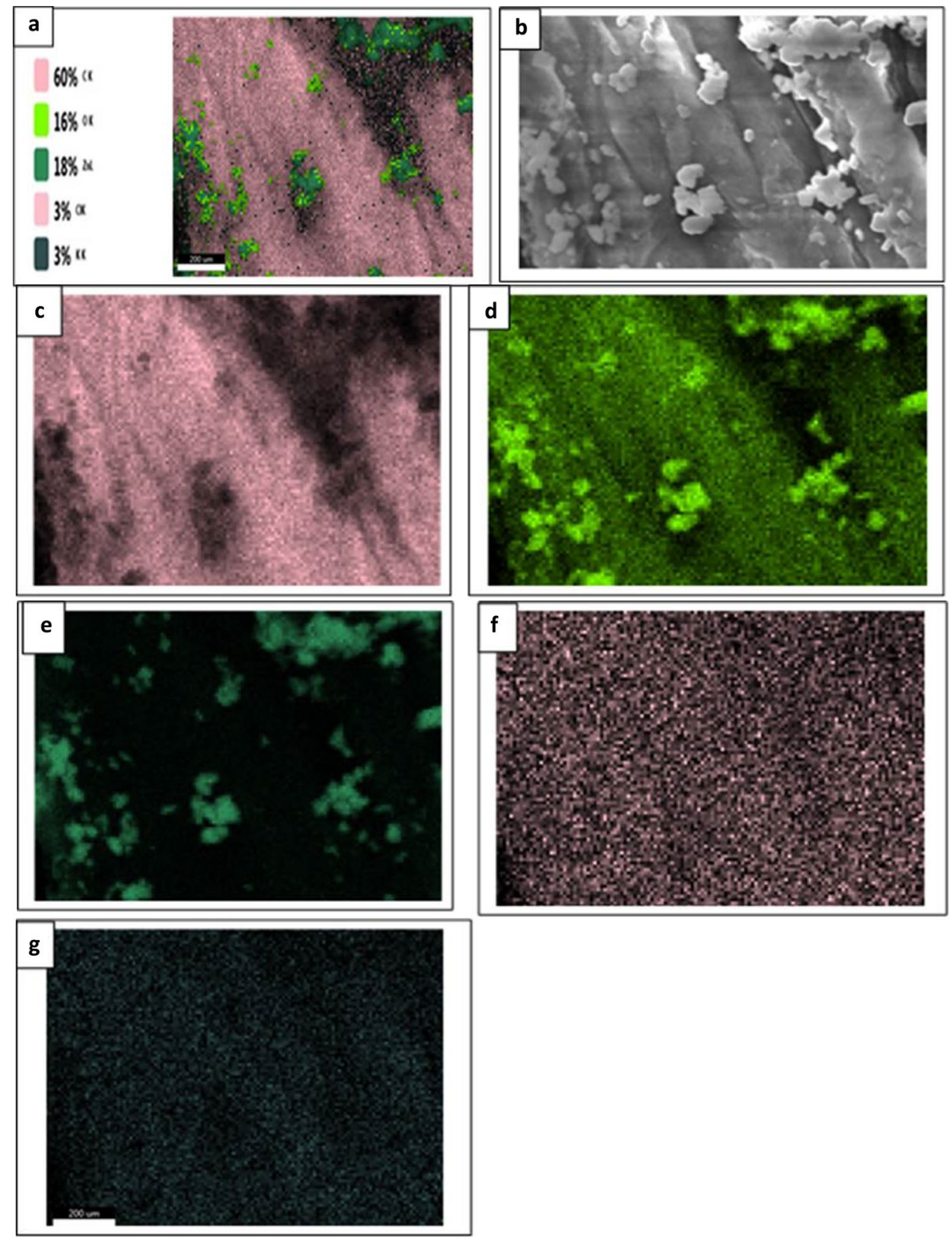
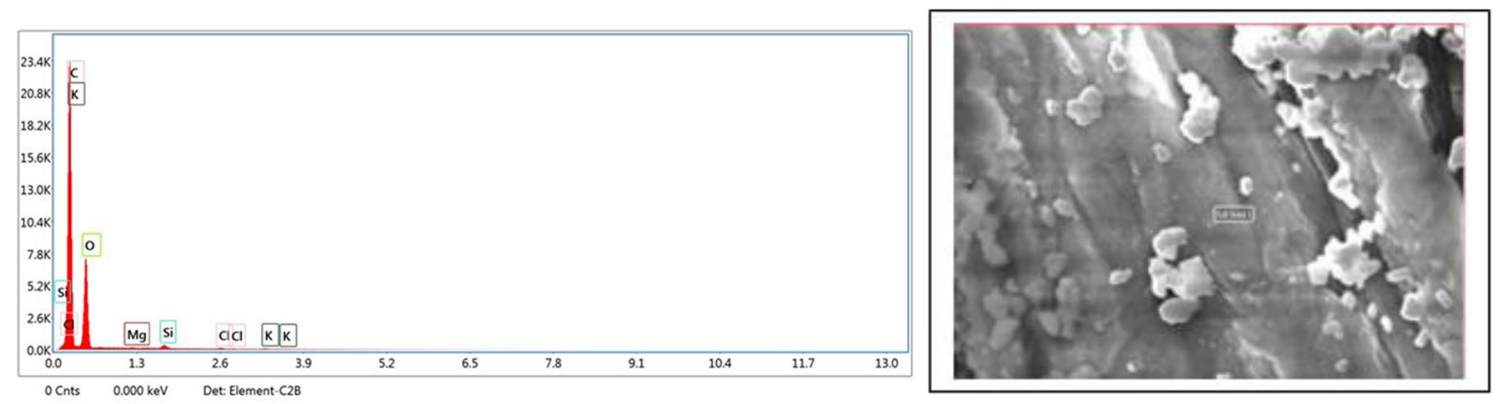

Fig. 6 EDX of the corn leaves and nanocomposite, kV: 20, mag: 100, takeoff: 45.4, live time (s): 60, amp time ( $\mu$ s): 3.84 , resolution: (eV) 129.5 
Table 2 Mapping of the nanocomposite (corn leaves and $\mathrm{ZnO})$

\begin{tabular}{lccclllll}
\hline \multicolumn{2}{l}{ Smart quant results } \\
\hline Element & Weight $\%$ & Atomic $\%$ & Net int & Error $\%$ & $K$ ratio & Z & A & F \\
\hline C K & 61.45 & 75.01 & 3490.44 & 6.77 & 0.2732 & 1.0474 & 0.4245 & 1.0000 \\
O K & 23.28 & 21.33 & 889.65 & 9.67 & 0.0403 & 1.0025 & 0.1727 & 1.0000 \\
ZnL & 13.85 & 3.11 & 734.09 & 3.33 & 0.0823 & 0.7619 & 0.7803 & 0.9996 \\
CIK & 0.60 & 0.25 & 92.66 & 2.72 & 0.0050 & 0.8498 & 0.9563 & 1.0148 \\
K K & 0.83 & 0.31 & 108.55 & 2.25 & 0.0072 & 0.8459 & 0.9958 & 1.0288 \\
\hline
\end{tabular}

are clear and other planes seemed disappeared. This is the same result of XRD patterns where only broad reflections exist.

Table 3 Langmuir isotherm fitting parameter

\begin{tabular}{lll}
\hline Langmuir isotherm & & \\
\hline & Iron & Nickel \\
\hline Corn leaves & $R^{2}=0.9867$ & $R^{2}=0.9911$ \\
ZnO & $R^{2}=0.9994$ & $R^{2}=0.9976$ \\
Nanocomposite (Corn leaves & $R^{2}=0.9983$ & $R^{2}=0.9961$ \\
and ZnO) & & \\
\hline
\end{tabular}

\section{Adsorption assessment}

The adsorption efficiency was determined using the following formula shown in Eq. 1 (Rajesh et al. 2020; Saravanan 2021):

Adsorption efficiency $=\left(\left(C_{\mathrm{i}}-C_{\mathrm{e}}\right) / C_{\mathrm{i}}\right) \times 100$,

where $C_{\mathrm{i}}$ and $C_{\mathrm{e}}$ are the initial and equilibrium concentrations $(\mathrm{mg} / \mathrm{L})$ of metal ion solution, respectively. The process of adsorption shows the efficiency of using the nanocomposite (corn leaves and $\mathrm{ZnO}$ ) in the best record time to removal of heavy metals ion (iron/nickel).
Fig. 7 HRTEM of corn leaves, a $0.5 \mu \mathrm{m}$, b $500 \mathrm{~nm}$, c $200 \mathrm{~nm}$, d SAED
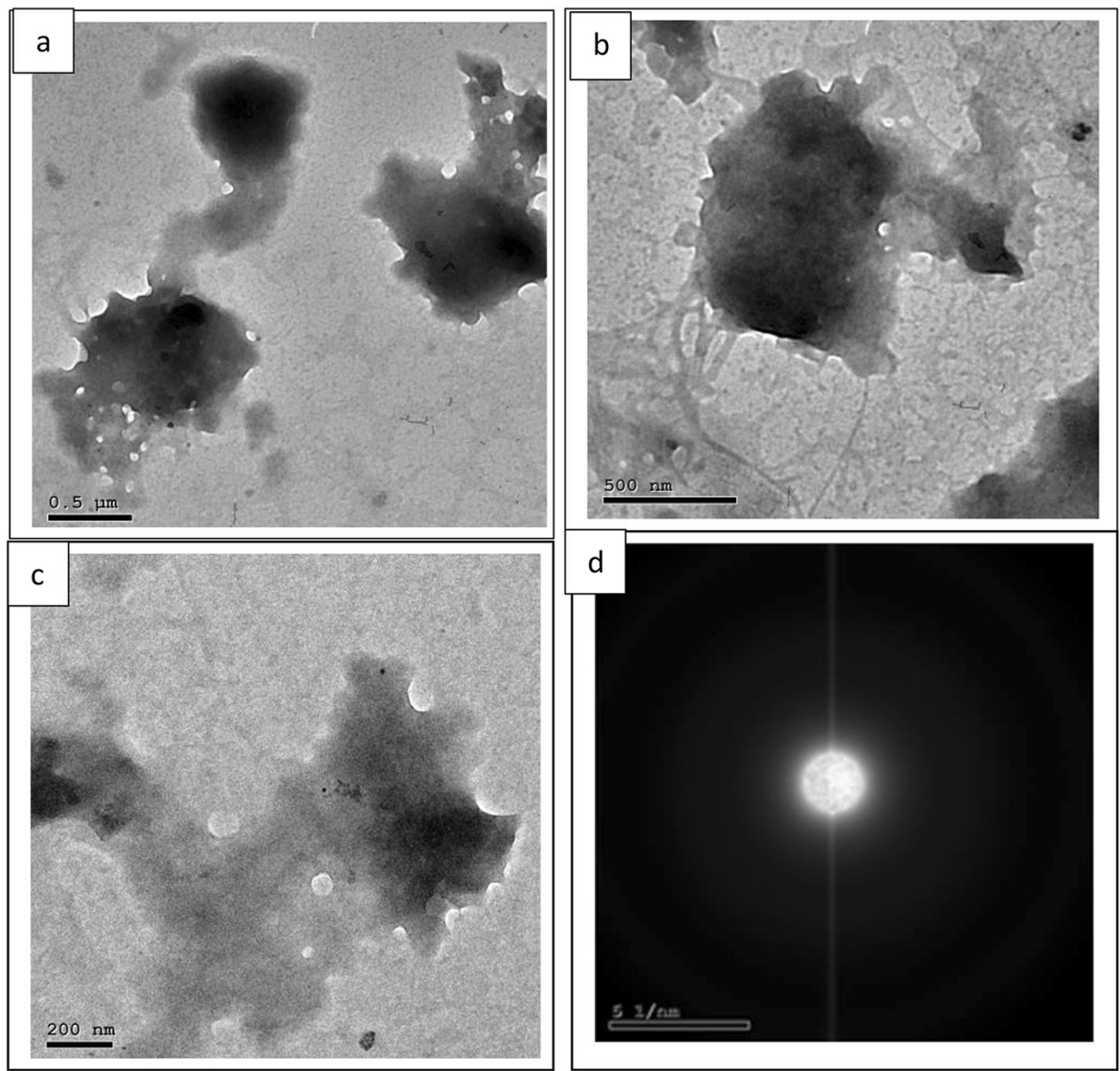
KACST مبريز 
Fig. 8 HRTEM of $\mathrm{ZnO}$, a $1 \mu \mathrm{m}$, b $500 \mathrm{~nm}, \mathbf{c} 200 \mathrm{~nm}$, d SAED
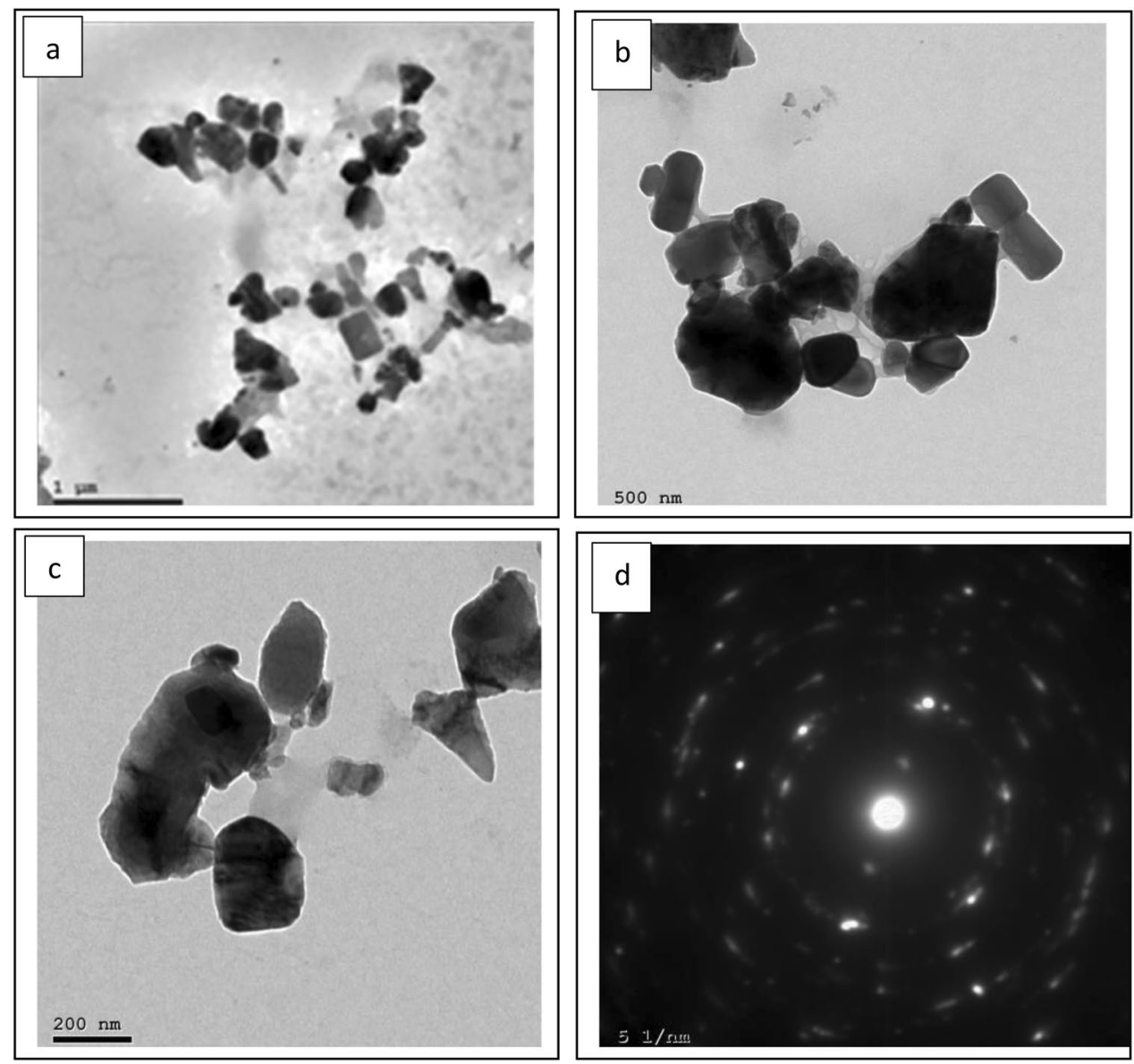

\section{Effect of $\mathrm{pH}$ value and saturation time on the removal efficiency of iron ions}

The process of removing iron ions from the aquatic environment using corn leaves, $\mathrm{ZnO}$ and nanocomposite are described here. The adsorption efficiency was plotted versus $\mathrm{pH}$; corn leaves revealed the highest adsorption efficiency of $85.83 \%$ at $\mathrm{pH} 7$ and the lowest efficiency of $59.4 \%$ at $\mathrm{pH} 3$. $\mathrm{ZnO}$ showed an excellent adsorption efficiency of $97.68 \%$ at $\mathrm{pH} 7$ and the lowest efficiency was $91 \%$ at pH 3. The nanocomposite had the highest adsorption efficiency of $96.4 \%$ at $\mathrm{pH} 7$ and the lowest efficiency of $84.56 \%$ at pH 3. Figure 10 shows the relationship between removal efficiency of Iron ions and $\mathrm{pH}$ at contact time $270 \mathrm{~min}$. From the results, the addition of $\mathrm{ZnO}$ to the nanocomposite leads to the enhancement of $(\mathrm{Fe})$ removal percentage using corn leaves from 85.8 to $96.4 \%$ at the same conditions.

Figure 11 shows the best adsorption and fastest saturation time at $\mathrm{pH} 7$ after $180 \mathrm{~min}$ for corn leaves, and the lowest saturation time was at $\mathrm{pH} 3$ after $240 \mathrm{~min}$. While the fastest saturation time of adsorption was at $\mathrm{pH} 7$ after $180 \mathrm{~min}$ and the slowest saturation time was at $\mathrm{pH} 3$ after $240 \mathrm{~min}$ for $(\mathrm{ZnO})$, the fastest saturation time of adsorption was at pH 7 after $180 \mathrm{~min}$ and the slowest saturation time was at pH 3 after 225 min for the nanocomposite. The value of saturation time is plotted versus the pH in Fig. 11 for the three investigated samples for the Fe ion removal process at room temperature. It was found that the saturation time is strongly dependent on the $\mathrm{pH}$ value of the solution. It is noted from the results that at $\mathrm{pH} 5$, the saturation time of the nano composite is higher than the saturation time of the other two precursors of corn-leaves and zinc oxide.

\section{Effect of $\mathrm{pH}$ value and time on the Ni ion removal efficiency}

It is shown on Fig. 12, the process of $\mathrm{Ni}$ ion removal at room temperature for various $\mathrm{pH}$ values (3-8). The best adsorption efficiency of corn leaves was $88.52 \%$ at $\mathrm{pH} 7$ and the weakest efficiency was $75.16 \%$ at $\mathrm{pH} 3$. The highest adsorption efficiency of $\mathrm{ZnO}$ was $99.07 \%$ at $\mathrm{pH} 7$ and the weakest efficiency was $91 \%$ at $\mathrm{pH} 3$. The nanocomposite 
Fig. 9 HRTEM of nanocomposite, a $500 \mathrm{~nm}$, b $200 \mathrm{~nm}$, c $1 \mu \mathrm{m}, \mathbf{d}$ SAED
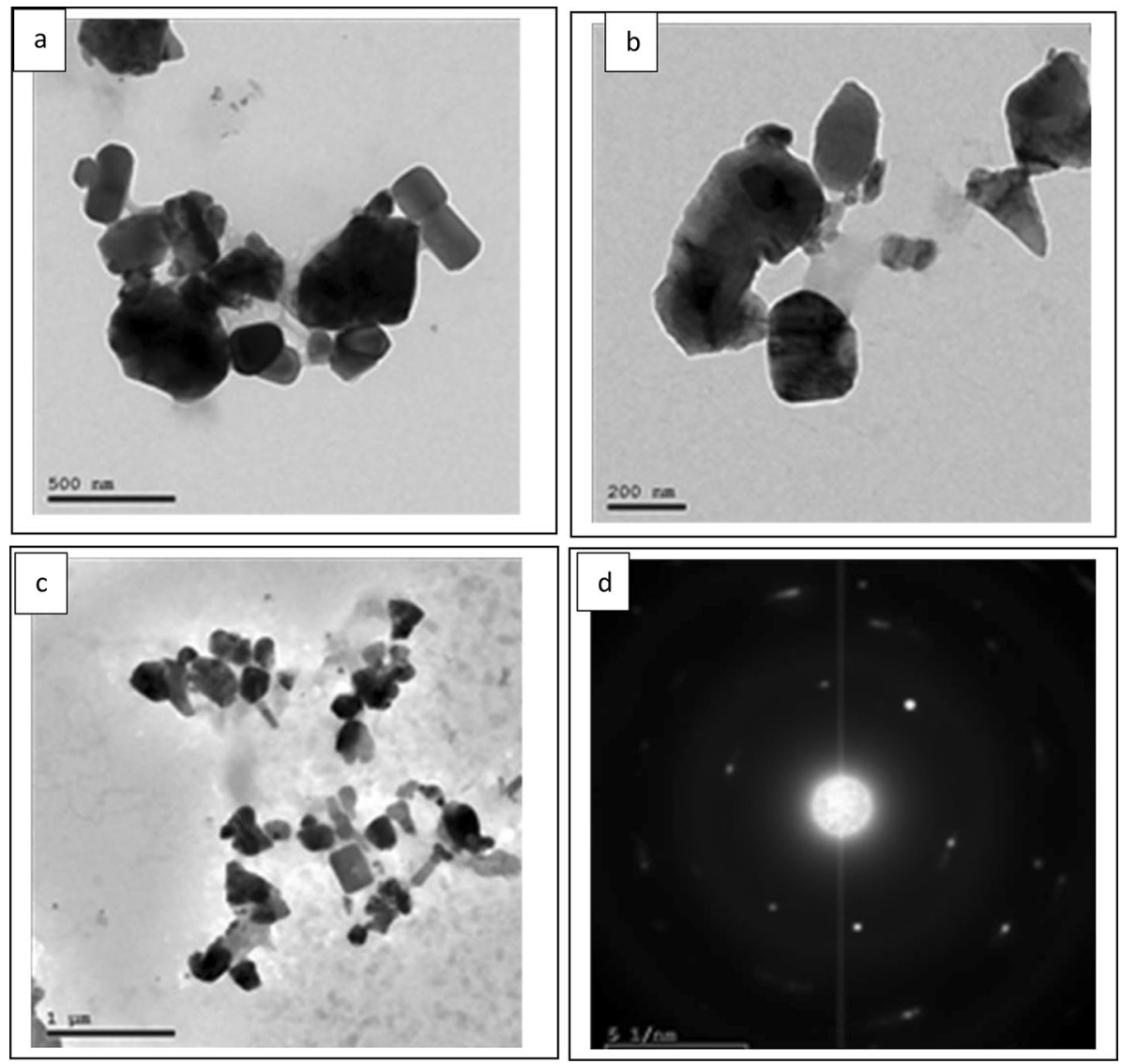

had the highest adsorption efficiency of $97.64 \%$ at $\mathrm{pH} 7$ and the lowest efficiency of $83.18 \%$ at $\mathrm{pH} 3$. It was discovered that the highest removal efficiency of nickel ion using

Fig. 10 The relationship between removal efficiency of Iron ions and $\mathrm{pH}$ nanocomposite as improved performance for corn leaves at contact time $270 \mathrm{~min}$.

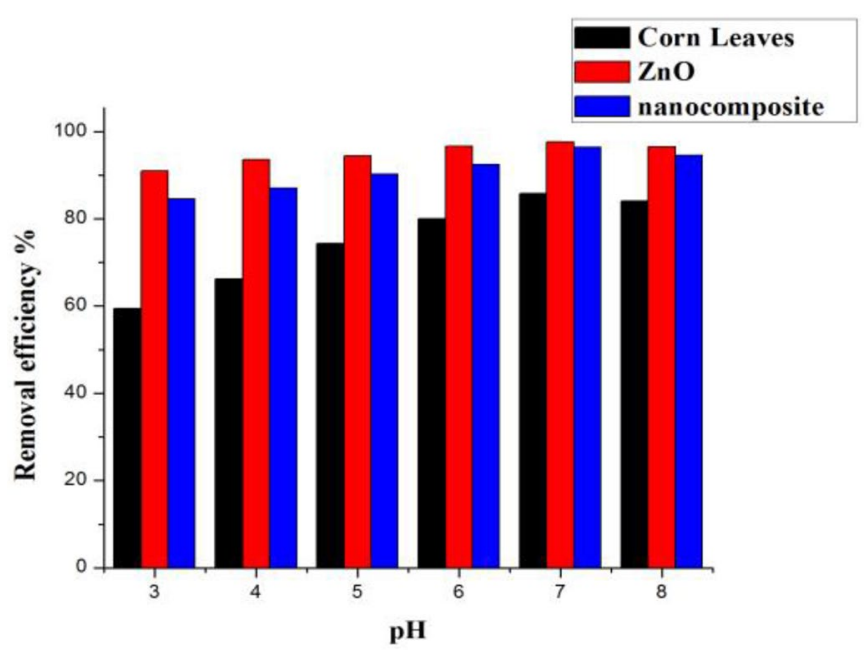




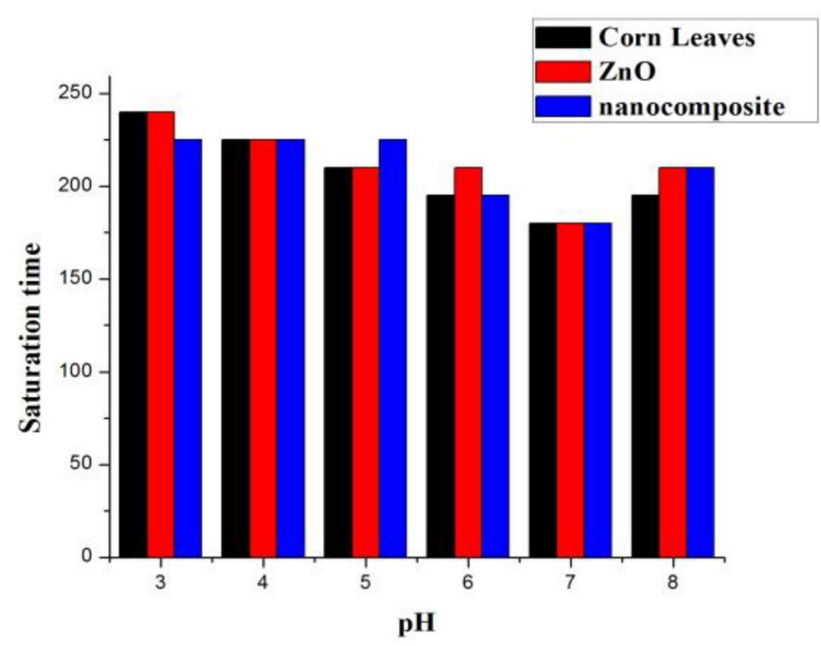

Fig. 11 The relationship between the saturation time and $\mathrm{pH}$

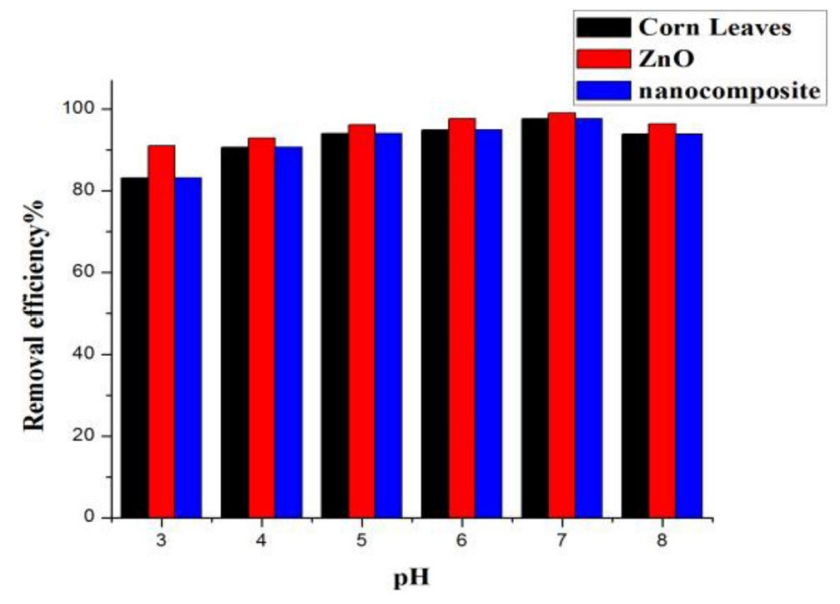

Fig. 12 The relationship between removal efficiency of nickel ions and $\mathrm{pH}$

From the results, the optimum $\mathrm{pH}$ value is 7 for the 3 investigated samples at a stable time. The best efficiency order is $99 \%$ for $\mathrm{ZnO}^{>} 97.85 \%$ for the nanocomposite and finally $88.52 \%$ for corn leaves. These results highlighted the role of $\mathrm{ZnO}$ nanoparticles in emphasizing the adsorption process of heavy elements using biomass.

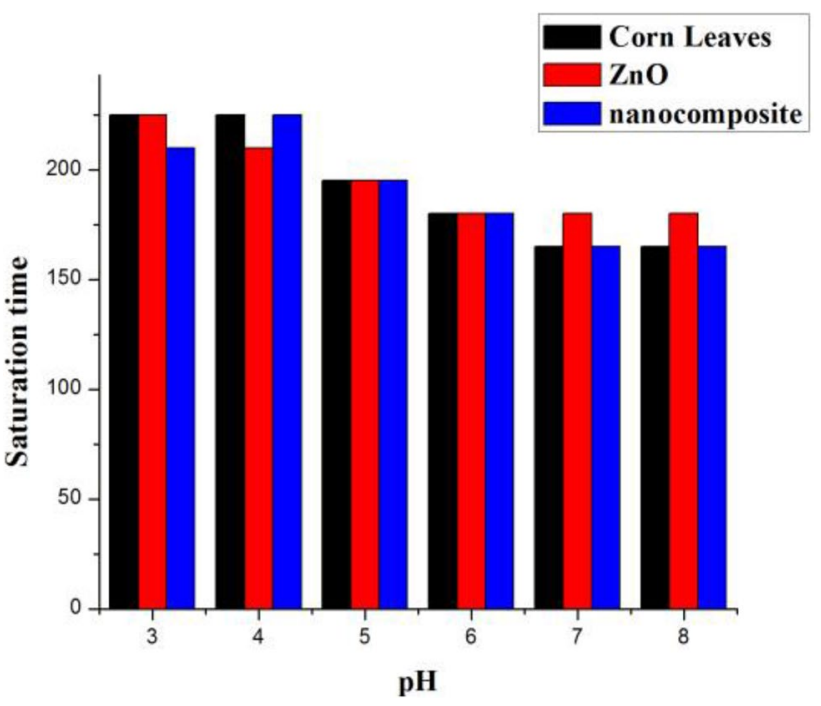

Fig. 13 The relationship between the saturation time and $\mathrm{pH}$ to the removal of nickel ions

Figure 13 shows the analysis of the saturation time to remove nickel ions from water vs $\mathrm{pH}$ values (3-8) for nickel ions using corn leaves, nanoparticles $(\mathrm{ZnO})$, and nanocomposite at room temperature. After $165 \mathrm{~min}, \mathrm{pH} 8 \mathrm{had}$ the fastest absorption saturation time, whereas $\mathrm{pH} 3$ and $\mathrm{pH} 4$ had the slowest absorption saturation time after $225 \mathrm{~min}$. The fastest saturation time of absorption was at $\mathrm{pH} 6, \mathrm{pH}$ 7 and $\mathrm{pH} 8$ after $180 \mathrm{~min}$, and the slowest saturation time was at $\mathrm{pH} 3$ after $225 \mathrm{~min}$ for $(\mathrm{ZnO})$ nanoparticles. After $165 \mathrm{~min}$, the fastest saturation time of absorption for nanocomposite was at $\mathrm{pH} 7$ and $\mathrm{pH} 8$, while the slowest saturation time was at $\mathrm{pH} 4$ after $225 \mathrm{~min}$. However, at $\mathrm{pH} 4$, the performance of the nano-composite is the best which propose that the composite perform better in the acidic medium.

\section{Adsorption validation models}

\section{Langmuir isotherm analysis}

$Q_{\mathrm{e}}(\mathrm{mg} / \mathrm{g})=\left(C_{\mathrm{i}}-C_{\mathrm{e}}\right) \times(V / W)$ 

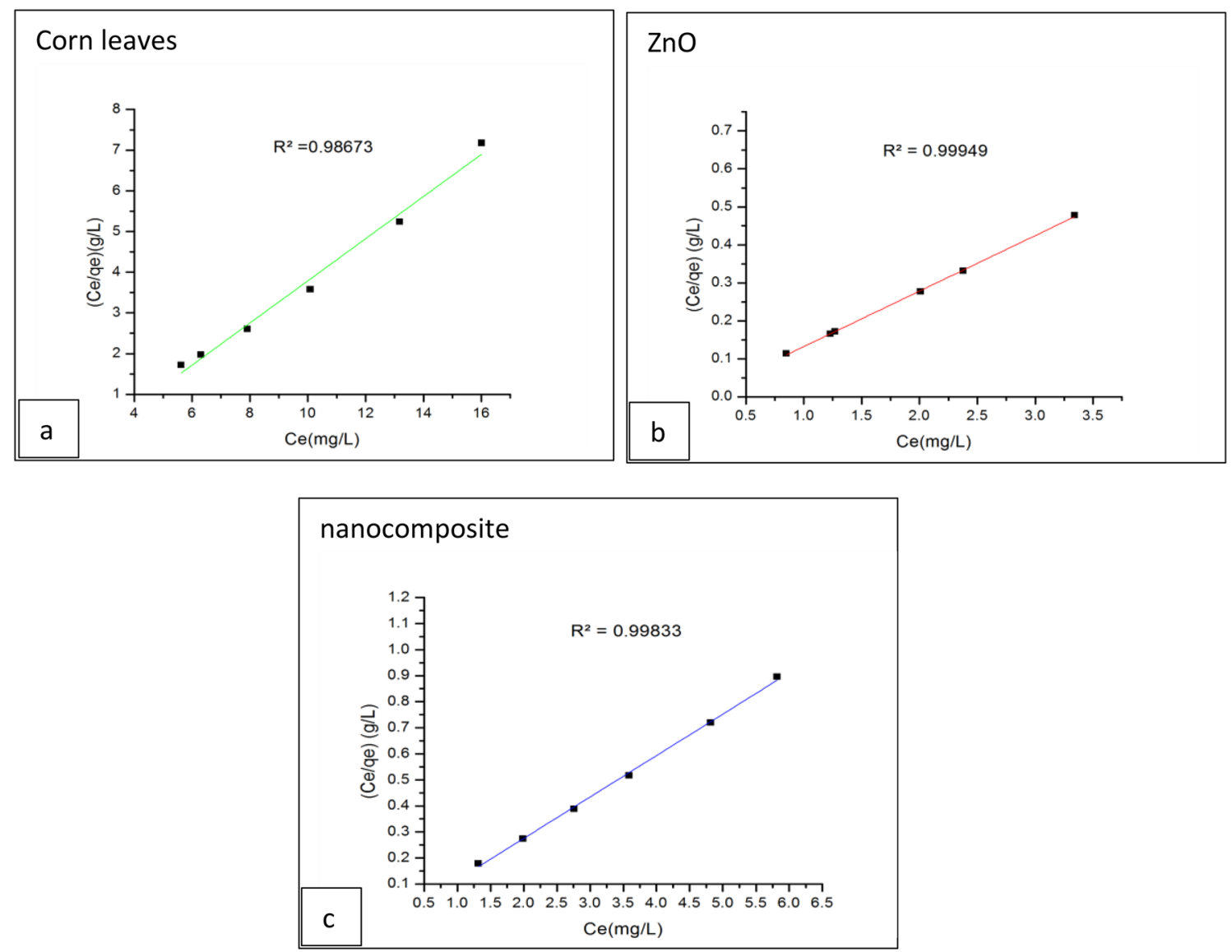

Fig. 14 a-c Langmuir isotherm analysis of iron ions removal

$$
\begin{aligned}
q_{\max } & =1 / \text { Intercept }, \\
K_{\mathrm{L}} & =1 /\left(\text { slope } \times q_{\max }\right), \\
R_{\mathrm{L}} & =1 /\left(1+C_{\mathrm{i}} \times K_{\mathrm{L}}\right),
\end{aligned}
$$

where $C_{\mathrm{e}}$ is the equilibrium concentration (mg/l), $V$ volume of the heavy metal solution in a litre, $W$ weight of the material in the experiment in $\mathrm{g}, C_{\mathrm{i}}$ is the initial concentration (mg/l). $K L(1 / \mathrm{mg})$ and $q_{\max }(\mathrm{mg} / \mathrm{g})$ are the Langmuir isotherm parameters (Sunil et al. 2021; Gyanendra and Mukesh 2021). From the results, the values of $R^{2}$ for the nano-composite is comparable with the nano zinc oxide which suggests that the synthetized nano composite has good applicability because of its low cost compared to the nano zinc oxide. However, the performance of the nano-composite for the removal of iron ions is slightly better than nickel ions (Figs. 14, 15).

\section{Freundlich isotherm analysis}

$\log q_{\mathrm{e}}=\log K_{\mathrm{F}}+(1 / n) \log C_{\mathrm{e}}$,

where $K_{\mathrm{F}}(\mathrm{mg}((\mathrm{l} / \mathrm{mg})-1 / n))$ and $n$ are the Freundlich isotherm parameters (Lina et al. 2021). The results suggests that the adsorption behavior of the nano composite is examined 


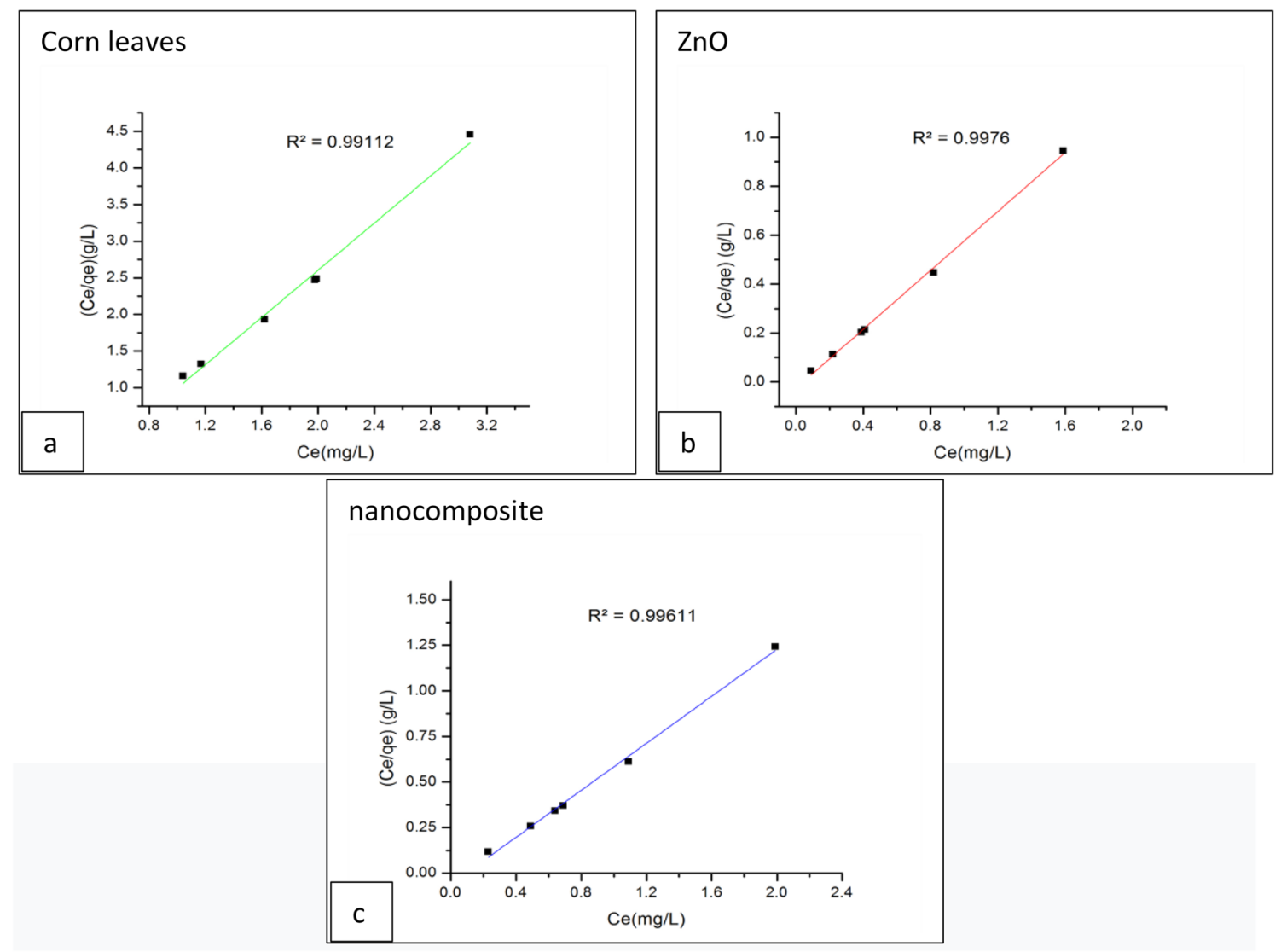

Fig. 15 a-c Langmuir isotherm analysis efficiency removal of nickel ions

Table 4 Freundlich isotherm fitting parameter

\begin{tabular}{lll}
\hline Freundlich isotherm & & \\
\hline & Iron & Nickel \\
\hline Corn leaves & $R^{2}=0.9555$ & $R^{2}=0.94$ \\
$\mathrm{ZnO}$ & $R^{2}=0.9483$ & $R^{2}=0.7743$ \\
Nanocomposite (corn leaves & $R^{2}=0.9362$ & $R^{2}=0.8338$ \\
and $\mathrm{ZnO})$ & & \\
\hline
\end{tabular}

better using Langmuir isotherm than Freundlich isotherm. However, even after examination of the experimental results using Freundlich isotherm, the performance of the nanocomposite for the removal of iron ions is still better than nickel ions (Table 4, Figs. 16, 17).

\section{Zeta size and zeta potential}

Zeta potential $(\mathrm{ZP})$ in millivolt $(\mathrm{mV})$ value of corn leaves, $\mathrm{ZnO}$, and nanocomposite material (corn leaves, $\mathrm{ZnO}$ ) was 

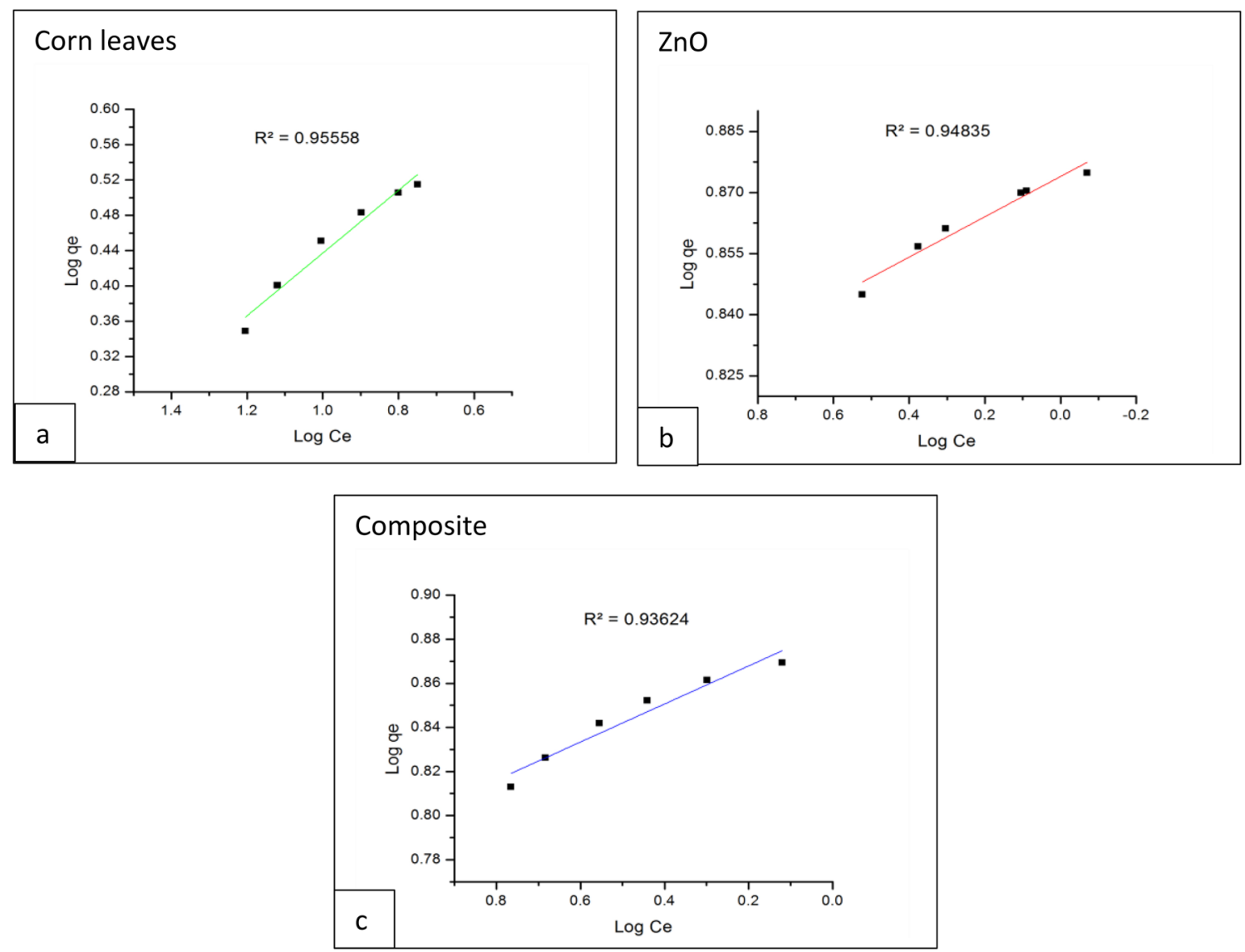

Fig. 16 a-c Freundlich fitting for the removal of iron

measured by a Zetasizer Malvern instrument. The results of the ZP analysis is demonstrated in Fig. 18a-f. The hydrodynamic diameter of the biomass particles (corn leaves) was found to be around (464.2) nm, which agrees well with previous characterization approaches. Those particles are negatively charged and have a potential value $(-7.91 \mathrm{mV})$, indicating that they are stable. In the case of $\mathrm{ZnO}$ nanoparticles, the hydrodynamic diameter here ensured particle aggregation, resulting in a size of about $(13.46 \mathrm{~nm})$. The presence of a negative charge on the surface of $\mathrm{ZnO}$ and its great stability have been discovered $(-91.3 \mathrm{mV})$. The nanocomposite exhibited a peak around (382.6 nm). Furthermore, with a large value of $(-17.1 \mathrm{mV})$. The zeta potential remained negative. These results are profitable because of the high elimination efficiency in a short period. We could deduce that the positively charged metal cations are electrostatically attracted to the negatively charged particles on the surface-active sites of the three samples under examination which agrees with many of the published research (Xuefeng et al. 2021; Saad et al. 2021; Roman 2014). 

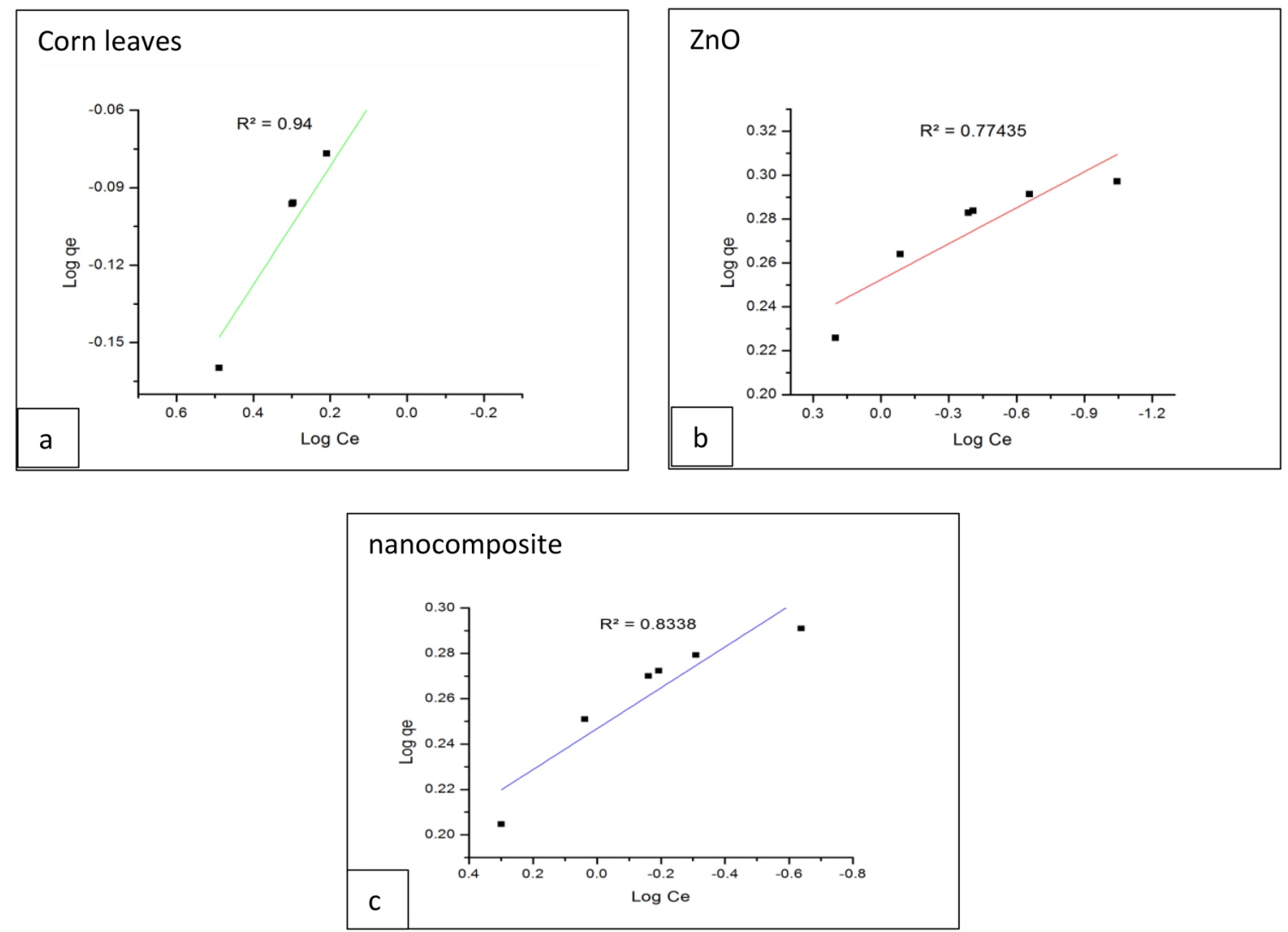

Fig. 17 a-c Freundlich fitting for removal of nickel ions

\section{Conclusion}

The results suggest that nanoparticles of $\mathrm{ZnO}$ possessing nanoparticle size $(30 \mathrm{~nm})$ helped to improve the capability of corn leaves through the synthesis of the nanocomposite. It acts as an excellent bio-adsorbent for heavy metals such as $\mathrm{Fe}$ and $\mathrm{Ni}$ at optimum conditions of $\mathrm{pH}$ and adsorption time. The adsorption assessment and validation results showed that the nanocomposite material is competitive compared to the nano zinc oxide. However, the integration of the biomass precursor and the nano zinc oxide resulted in low-cost applicable adsorbent for removal of heavy metals from aquatic environment. However, this approach may help to tackle two problems of agriculture solid waste such as corn leaves and heavy metals removal from the aquatic environment. The results suggest testing the proposed nanocomposite for industrial application. 
Fig. 18 Zeta size a corn leaves, b $\mathrm{ZnO}$ and $\mathbf{c}$ nanocomposite respectively
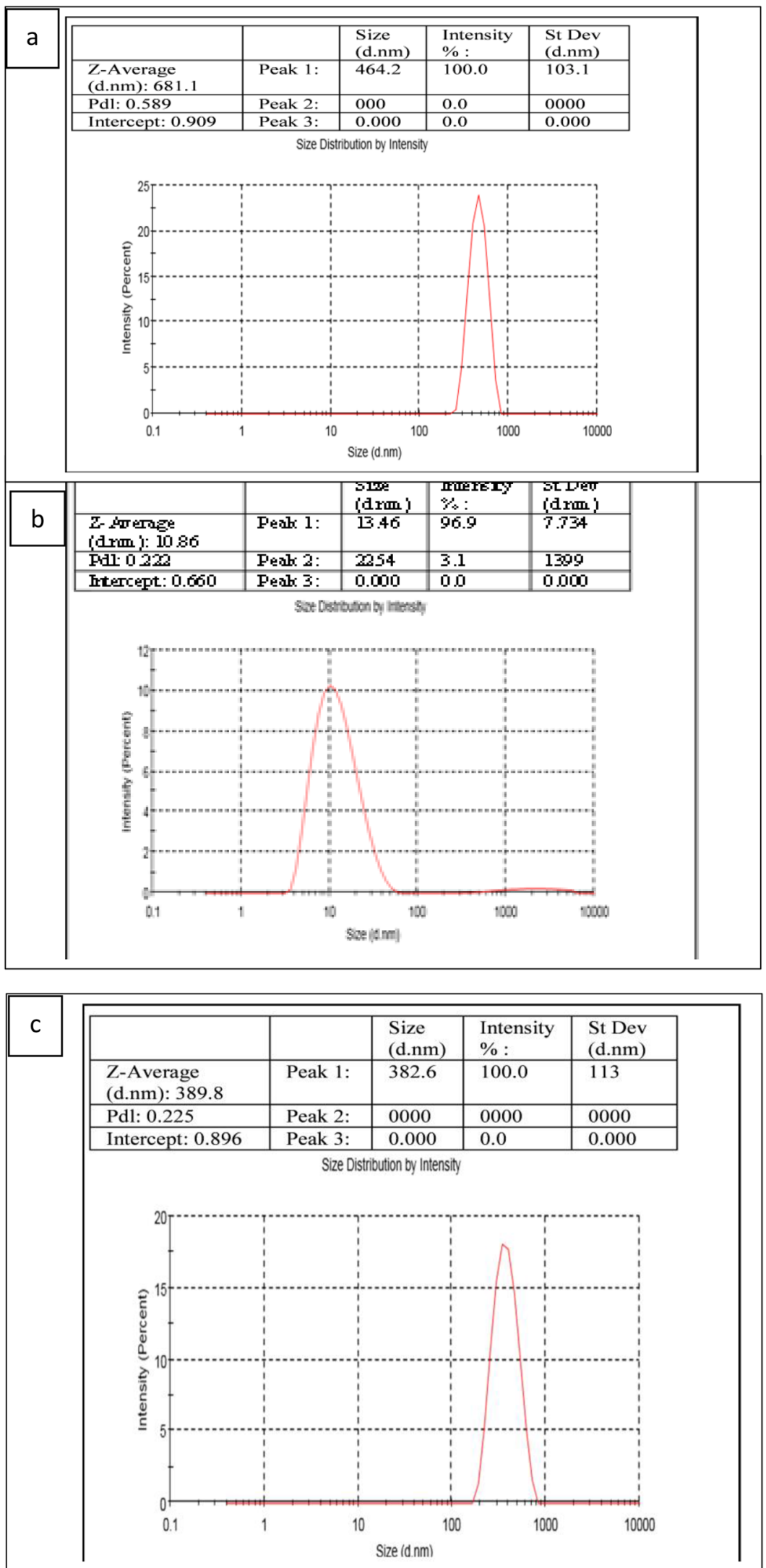
Funding Open access funding provided by The Science, Technology \& Innovation Funding Authority (STDF) in cooperation with The Egyptian Knowledge Bank (EKB).

\section{Declarations}

Conflict of interest On behalf of all authors, the corresponding author states that there is no conflict of interest. All the authors do not have any SOURCE OF FINANCIAL SUPPORT related to this publication.

Open Access This article is licensed under a Creative Commons Attribution 4.0 International License, which permits use, sharing, adaptation, distribution and reproduction in any medium or format, as long as you give appropriate credit to the original author(s) and the source, provide a link to the Creative Commons licence, and indicate if changes were made. The images or other third party material in this article are included in the article's Creative Commons licence, unless indicated otherwise in a credit line to the material. If material is not included in the article's Creative Commons licence and your intended use is not permitted by statutory regulation or exceeds the permitted use, you will need to obtain permission directly from the copyright holder. To view a copy of this licence, visit http://creativecommons.org/licenses/by/4.0/.

\section{References}

Ahamad T, Naushada M, Al-Shahranib T, Al-hokbanya N, Alshehria SM (2020) Preparation of chitosan-based magnetic nanocomposite for tetracycline adsorption: kinetic and thermodynamic studies. Int J Biol Macromol 147:258-267

Ahmaruzzaman M, Gupta VK (2011) Rice husk and its ash as low-cost adsorbents in water and wastewater treatment. Ind Eng Chem Res 50:13589-13613

Ahmed SF, Mofijur M, Samiha N, Anika TC, Nazifa R, Md Alhaz U, Abrar I, Mahlia TMI, Hwai CO, Wen YC, Pau LS (2021) Recent developments in physical, biological, chemical, and hybrid treatment techniques for removing emerging contaminants from wastewater. J Hazard Mater 416:125912

Aruna Y, Nisha B, Ashok KS, Surender K (2021) Advances in decontamination of wastewater using biomass-based composites. Sci Total Environ 784:147108

Aya E, Reham SE, Sarah HA, Nahla M, Dina S, El-Dek SI, Zaki AH (2021) Innovative bio templates for the synthesis of $\mathrm{ZnO}$ nanoparticles with versatile morphologies. J Sol Gel Sci Technol 99:326-338

Babel S, Kurniawan TA (2003) Low-cost adsorbents for heavy metals uptake from contaminated water: a review. J Hazard Mater 97:219-243

Ferin FA, Jothi MR, Mohamed RM, Sakthipandi K (2021) Enhancing structural and optical properties of $\mathrm{ZnO}$ nanoparticles induced by the double co-doping of iron and cobalt. Mater Today Proc. https://doi.org/10.1016/j.matpr.2021.06.433 (corrected proof)

Fernando CB, Micaela GC, William RR, Dhivya JP, Richard AB, John BA (2020) Improved conversion of residual MSW biomass waste to sugars using online process monitoring and integrated contamination control. Biores Technol Rep 13:100612

Gupta VK (2009) Application of low-cost adsorbents for dye removala review. J Environ Manag 90:2313-2342
Gupta VK, Carrott PJM, Ribeiro MML (2009) Low-cost adsorbents: growing approach to wastewater treatment-a review. Crit Rev Environ Sci Technol 39:783-842

Gyanendra PS, Mukesh KR (2021) Dielectric study of ZnO nanorods synthesized by thermal decomposition method. Mater Today Proc 46(12):5878-5880

Jingjing S, Wude Y, Meijun Z, Meichen F, Lujie X, Guangwei D (2021) Estimation of water content in corn leaves using hyperspectral data based on fractional-order Savitzky-Golay derivation coupled with wavelength selection. Comput Electron Agric 182:105989

Lankathilaka KPW, de Silva RM, Mantilaka MMMGPG, de Silva KMN (2021) Magnetite nanoparticles incorporated porous kaolin as a superior heavy metal sorbent for water purification. Groundwater Sustain Dev 14:100606

Lina RA, Stéphan RG, Stéphane Z, Stoll S (2021) Nanoplastics adsorption and removal efficiency by granular activated carbon used in drinking water treatment process. Sci Total Environ 791:148175

Medha B, Ranjana J, Rekha B, Reetu S (2021) Serrated hexagonal ZnO nanoparticles: synthesis and its characterization. Mater Today Proc. https://doi.org/10.1016/j.matpr.2021.05.686

Mohan D, Sarswat A, Ok YS, Pittman CU Jr (2014) Organic and inorganic contaminants removal from water with biochar, a renewable, low cost and sustainable adsorbent-a critical review. Bioresour Technol 160:191-202

Rajesh S, Anita Y, Sonia A, Nawal K (2020) To study the structural properties of cobalt doped tin oxide nanostructured by using Williamson-Hall and size-strain plot methodology. Mater Today 44(6):4651-4656

Roman M (2014) Particle size and zeta potential of ZnO. APCBEE Proc 9:13-17

Saad A, Abeeb A, Guenther G, Stephen A, Ibrahim A, Ahmed G (2021) Langmuir adsorption isotherm in unconventional resources: applicability and limitations. J Pet Sci Eng 207:109172

Saravanan S (2021) Functional, structural and morphological property of green synthesized silver nanoparticles using Azadirachta indica leaf extract. Mater Today Proc. https://doi.org/10.1016/j.matpr. 2021.03.227 (corrected proof)

Sunil M, Shweta J (2021) Effect of reaction temperature and time on the physical properties of CTAB-assisted hydrothermally grown $\mathrm{ZnO}$ nanostructures. Mater Today Proc. https://doi.org/10.1016/j. matpr.2020.12.741 (corrected proof)

Xiao-long H, Hang H, Mulualem T, Qi-yan L, Zong-xun L, Chen-lu Z, Si-qi H, Li-ping C, Ai-qin L (2020) Lead contamination alters enzyme activities and microbial composition in the rhizosphere soil of the hyperaccumulator Pogonatherum crinitum. Ecotoxicol Environ Saf 207:111308

Xuefeng X, Yuanyuan Y, Yongjun S, Xing Z, Aowen C (2021) Heavy metal removal from aqueous solutions by chitosan-based magnetic composite flocculants. J Environ Sci 108:22-32

Yaowei H, Qiongfen Y, Ming L, Shaoxuan J, Jie F, Le Z, Zhaohui Y (2021) Surface modification of activated carbon fibre by low-temperature oxygen plasma: Textural property, surface chemistry, and the effect of water vapour adsorption. Chem Eng J 418:129474

Zhaojin L, Xiaoyong Y, Bingjie W, Hui L, Zhishan B (2021) Coalescence-adsorption coupling treatment instead of alkaline washingwater washing process for efficient removal of sulfuric acid and sulfates. Process Saf Environ Prot 151:311-323

Publisher's Note Springer Nature remains neutral with regard to jurisdictional claims in published maps and institutional affiliations. 